\title{
THE IMPACT OF AN EDUCATIONAL PROGRAM FOR MOTHERS OF CHILDREN WITH OTITIS MEDIA ON THE PREVENTION OF ITS RECURRENCE AT ZAGAZIG UNIVERSITY HOSPITAL \\ ${ }^{1}$ Reda Mohamed Abd El-Gowad, ${ }^{2}$ Fawzia Elsayed Abusaad, and ${ }^{3}$ Rehab Abd El Aziz El-Sayed \\ ${ }^{1}$ M.Sc. Pediatric Nursing, Faculty of Nursing,Zagazig University \\ ${ }^{2}$ Professor of Pediatric Nursing, Faculty of Nursing, Mansoura University \\ ${ }^{3}$ Lecturer of Pediatric Nursing, Faculty of Nursing, Mansoura University E-mail of corresponding author mrmry2005@gmail.com
}

\begin{abstract}
:
Background: Otitis media is a common pediatric condition that affects most children by their second birthday and untreated cases of otitis media can possibly cause long term complications. This study aimed to evaluate the impact of implementing educational program for mothers about preventing of the recurrent otitis media. Design: Quasiexperimental design was conducted at pediatric ENT outpatient clinic at Zagazig University Hospital on a sample of 118 mothers who had children suffering from otitis media and attending the previously mentioned setting to manage their children. Tools of data collection: Data were collected by using child assessment sheet and structured interview questionnaire for mothers. Results: About one quarter of the studied children had recurrent otitis media once or twice episode per year and less than two thirds their recurrence were four episodes or more per year before program. After implementation of the educational program the children improved as the majority of children had recurrent otitis media once or twice episode per year. Conclusion: There was a positive impact of the educational program in improving mothers' knowledge as well as their reported practices about otitis media as well as on the recurrence of otitis media. Recommendations: Regular and continuous health educational programs are essential for improving the mothers' knowledge and their reported practices regarding their children having otitis media.
\end{abstract}

Keywords:, Children, Educational Program, Mothers, Prevent recurrence, Otitis media

\section{Introduction:}

Otitis media $(\mathrm{OM})$ is one of the most common illnesses, of infancy and childhood. Infants have several features that predispose them to suffer from otitis media more frequently as more horizontal, shorter and wider Eustachian tubes. Every infant in a family has a unique charm and value. This presents a great challenge for the caregivers and the health team to maintain the health and well-being for those infants (Scott and Hunt, 2013).

Otitis media is a disease involving middle ear effusion and inflammation. The term otitis media is often used to describe any of a continuum of related diseases: acute otitis media (AOM), recurrent acute otitis media (RAOM), otitis media with effusion, and chronic otitis media with effusion (COME). Causative organisms include viruses as respiratory syncytical virus, influenza (type A or B), adenovirus, parainfluenza virus, enterovirus and rhinovirus. Bacterial causes involve haemophilus influenza and maroxella catarrhalis (Barenkamp, 2015).

Otitis media is a supportive infection of the middle ear cavity. Bacteria gain access to the middle ear when the normal patency of the Eustachian tube is blocked by upper airway infection or 
hypertrophied adenoids. Air trapped in the middle ear is resorbed, creating negative pressure in this cavity and facilitating reflux of nasopharyngeal bacteria. Obstructed flow of secretions from the middle ear to the pharynx combined with bacterial reflux leads to infected middle ear effusion. (Padmaja, 2015)

During the first year of life the rate of otitis media is $45.35 \%$. The prevalence of otitis media in Egypt was found to be $41.7 \%$ (Naguib et al., 2013). Risk factors for otitis media include:infants'age less than 1 year, large family size, low level of maternal education, parental smoking, faulty position during breastfeeding or bottle feeding, craniofacial defects and previous upper respiratory tract infections (Humaid, 2014). Acute symptom course is known to be present in most types of otitis media. Infants mainly manifest otalgia, otorrhea, hyperthermia, irritability, restlessness, screaming, anorexia, vomiting, pulling, rubbing, of the ear and falling of the hair around the affected ear (Djalilian, 2015) Complications of otitis media include conductive hearing loss and sensorineural hearing loss. The infection of acute otitis media can spread to surrounding tissues, causing mastoiditis or intracranial complications such as meningitis or brain abscess. Inflammation and pressure from otitis media may result in tympanosclerosis (scarring of the tympanic membrane), perforation of the tympanic membrane, and cholesteatoma (pus and debris in the middle ear) (Ruiz et al., 2015). Prevention of otitis media can be probably achieved via administration of pneumococcal conjugate vaccines and prophylactic antibiotics. Surgical interventions include: myringotomy, Tympanocentesis, adenoidectomy, tonsillectomy and tympanostomy tube insertion (Djurhuus et al., 2015). Participation in the prevention of occurrence and recurrence of otitis media is the mothers' responsibility. Mothers' knowledge should be enhanced by providing education and follow up for their information. Knowledge about methods to prevent upper respiratory tract infections is crucial in prevention of otitis media in infants. Mothers' knowledge is greatly affected by the previous experiences and practices with their siblings (Hansen et al., 2015). Practices that should be encouraged and carried out as efforts for preventing otitis media are: promoting healthy breastfeeding practices, healthy hygienic practices at home such as hand washing and ear care. Education about medication administration and healthy cooking and preparation of food at home are also of great importance (Smith et al., 2012). Pediatric nurses' role involves therapeutic and preventive interventions. Follow up for the treatment regimens, screening for complications, parent education and support are crucial for achieving a better outcome. Compliance with treatment and periodic explanations or checkups plays an important role in the recovery (Yousef et al., 2015). Otitis media continues to affect a great portion of children around the world annually; therefore mothers' knowledge and practical knowledge should be assessed to highlight the predisposing factors and care of otitis media to decrease the possible related complications and prevent recurrent of otitis media.

\section{Aim of the study}

This study aimed to evaluate the impact of implementing educational program for mothers about preventing of the recurrent otitis media through:

1. Assessment of mothers' knowledge and practice regarding prevention of the recurrence otitis media.

2. Design educational program based on the actual need assessment of mothers. 
THE IMPACT OF AN EDUCATIONAL PROGRAM FOR etc...

3. Implementation and evaluation the
impact of educational program on
prevention of recurrente otitis media.
Subjects and Method
Design: A quasi- experimental design was
used in carrying out the study.
Setting: This study was conducted at
pediatric ENT outpatient clinic at Zagazig
University Hospital that provides services
to all Sharqia governorate children.

Subjects: The study included a convenient sample of 118 mothers who had children suffering from otitis media and attending the previously mentioned setting to manage their children.

Tools and technique of data collection:

Data were collected through the following tools:

Tool (I): Child assessment sheet. It was developed by the researcher after reviewing the related literature it consists of the following parts: (Appendix I)

Part 1): Characteristics of child such as age, six, ranking, siblings' numbers and attending nursery school.

Part 2): History about infant feeding, using a pacifier, bottle feeding, presence of food allergy, day care attendance, air pollution, passive smoking, recent illness(cold, sinus infection) and presence of congenital anomalies(cleft lip and palate) that collected from mothers.

Part 3): Clinical data that collected from child file and include: Time start of disease, disease duration, frequency per year, associated complication, and number of doctor visit and drug prescription.

Tool (II): Structured interview questionnaire for mothers developed by the researcher in Arabic language after reviewing the related literature (Appendix II) it consists of the following:

a- Socio-demographic data of mothers (age, level of education and occupation). Socio-economic Status Scale that assessed by (El-Gilany, et al., 2012). b- Mother's knowledge about otitis media such as 88 questions related to mother's knowledge about definitions, types of otitis media, causes, risk factors, signs and symptoms, complications and prevention.

Scoring of mothers' knowledge:

Each (correct) answer was given one mark (1) and (incorrect) answer was given (zero). The total numbers of questionnaire regarding knowledge of mothers were 88 questions. Mothers' knowledge was classified according to Thabet et al., (2016) into the following: Good for score $65 \%$ and more, average for score $50 \%$ less than $65 \%$ and poor for score less than $50 \%$.

c- Mother's practical knowledge about care given to their children during attack (24) questions was developed by the researcher to assess mother's actual intervention regarding onset of signs of ear infection, ear pain, wax material in the ear, followup and treatment and care of ear during inflammation.

Scoring system of mother's practical knowledge:

Each items was given score (2) for done, sometimes done (1) score, and not done (0) score. The total scores of mothers' practical knowledge were 48 for all the mother practices carried out for the child with otitis media and was classified according to (Elsayed, 2016) into satisfactory practice $(>50 \%)$ and unsatisfactory practice $(<50 \%)$.

Methods:

- Before conducting this study, an official approval was obtained from the responsible authorities.

- The developed tools were tested for their reliability using Alpha Cronbach's coefficient test. The alpha reliability for tool (1) was 0.785 , tool (2) was 0.876 and the tool (3) was 0.88 .

- The educational program was prepared by the researcher. It was specially designed in a simple Arabic language 
to meet the needs of mothers for otitis media.

- An informed oral consent was gained from mothers after explaining the purpose of the study.

- Mothers' right to withdraw from the study at any time was ascertained as well as the confidentiality of data and anonymity.

- Actual fieldwork of present study carried out from first of January up to the end of June (2016), in the study setting. The study lasted for 6 months spent in conducting the pre/post- test and 6 months later follow up and implementing program.

- The contents of the program were delivered through four sessions. Statistical Analysis

- Organizing, categorizing, tabulating and analyzing the collected data was done by using SPSS software version 16.

- Presenting the data were done in tables and graphs as frequencies and percentages.

- A significant finding indicated when the $\mathrm{P}$ value of $<0.05$

- Comparison of categorical variables was done using the Chi square test used to estimate statistical significance between variables.

\section{Results}

Table (1) revealed that, more than half of the studied mothers' age (56.8\%) ranged between 20 to less than 30 years old. More than half of the studied mothers $(61.9 \%)$ were living in rural areas, while the rest of them were living in urban areas. Regarding to mothers' level of education, more than two fifths of them $(41.5 \%)$ were secondary. As for their occupation, more than half of the studied mothers $(62.7 \%)$ were employed. Regarding to socioeconomic level, almost more than half of the studied mothers $(57.6 \%)$ were low.

Table (2) revealed that, more than two fifths of the studied children $(40.7 \%)$ were in the age group from one year to less than 3 years of age. In relation to sex, more than half of the studied children $(56.8 \%)$ were males. As regards to birth order, more than half of the studied children were ranked as the first child (60.2\%).Regarding the number of siblings; it was found that more than half of the studied children $(56.8 \%)$ were from 4 and more .As regards to nursery school attendance, less than two thirds $(61.0 \%)$ of the studied children attending nursery schools, while about one quarter $(27.1 \%)$ of them attending at age $3<5$ years.

Table (3) Before implementation of the educational program, $28.0 \%$ of children had recurrent otitis media once or twice episode per year,5.9\% their recurrence were 3 or 4episodes per year, and $61.0 \%$ their recurrence were 4episodes or more per year before program. After implementation of the educational program the children improved as $92.4 \%$ of children had recurrent otitis media once or twice episode per year. Highly statistical significant differences were found between before\& post 6 months of the program implementation regarding to the frequency of recurrent otitis media.

Levels of mothers' reported practice, before, immediately after and post 6 months of the program implementation. Figure (1) shows that, more than two fifths of the studied mothers $(43.2 \%)$ had "unsatisfactory" reported practice before the program while immediately after the program implementation and 6 months later, this percent decreased to $33.1 \%$ and $27.1 \%$ respectively. 
THE IMPACT OF AN EDUCATIONAL PROGRAM FOR etc...

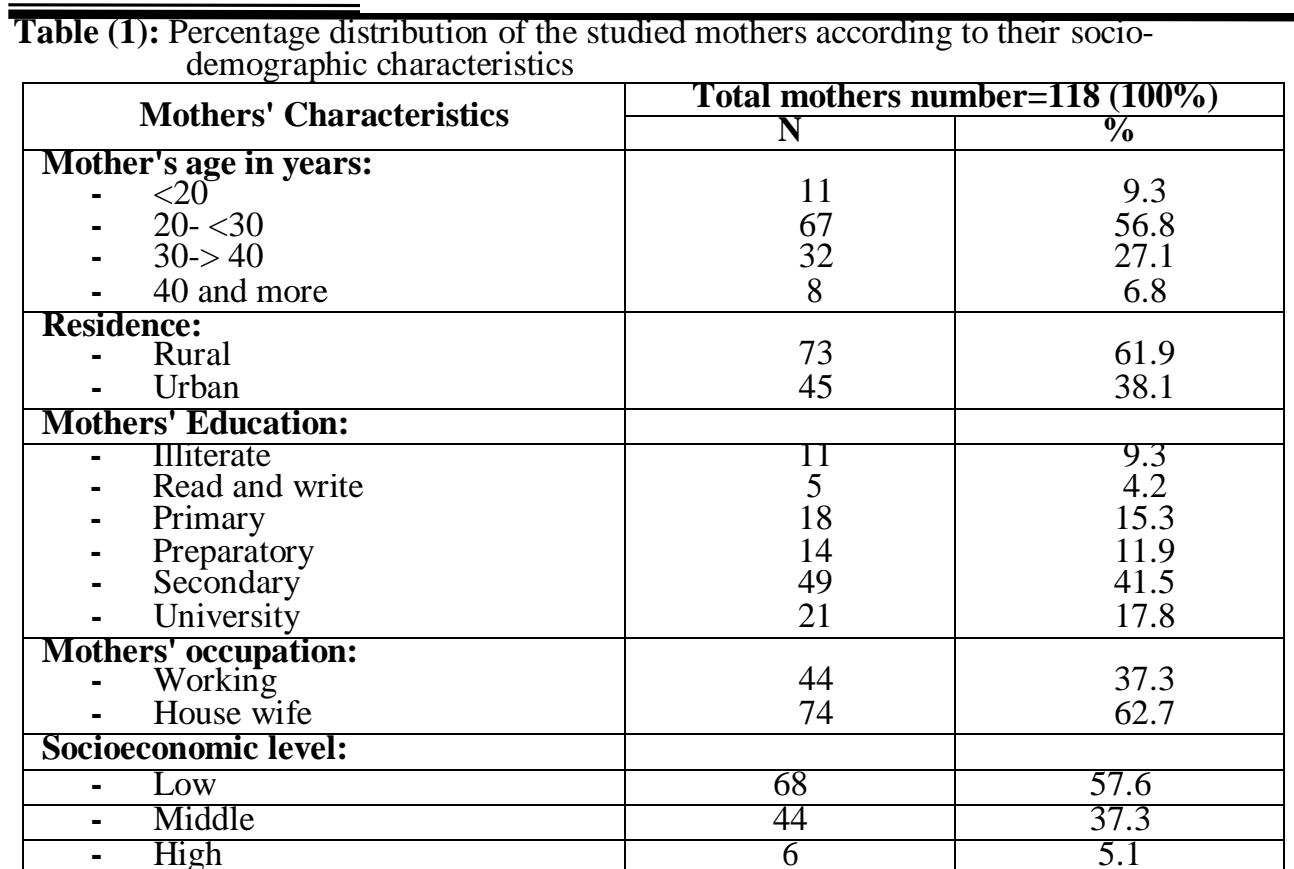

Table (2): Percentage distribution of the studied children according to their characteristics and nursery school attendance.

\begin{tabular}{|c|c|c|}
\hline \multirow{2}{*}{ Child Characteristics } & \multicolumn{2}{|c|}{ Total children number $=118(100 \%)$} \\
\hline & $\mathbf{N}$ & $\%$ \\
\hline \multicolumn{3}{|l|}{ Child age in years: } \\
\hline$-<1$ & 25 & 21.2 \\
\hline$-1<3$ & 48 & 40.7 \\
\hline$-3<5$ & 32 & 27.1 \\
\hline-5 to 6 & 13 & 11.0 \\
\hline \multicolumn{3}{|l|}{ Sex: } \\
\hline - Male & 67 & 56.8 \\
\hline - Female & 51 & 43.2 \\
\hline \multicolumn{3}{|l|}{ Birth order: } \\
\hline$-1^{\mathrm{st}}$ & 71 & 60.2 \\
\hline$-2^{\text {III }}$ & 37 & 31.4 \\
\hline$-3^{\text {ra }}$ & 7 & 5.9 \\
\hline$-4^{\mathrm{m}}$ & 3 & 2.5 \\
\hline $\begin{array}{c}\text { Number of siblings: } \\
-\quad<3 \text { children }\end{array}$ & 50 & 42.4 \\
\hline - 4 and more & 67 & 56.8 \\
\hline $\begin{array}{l}\text { Attending nursery school: } \\
-\quad \text { Yes } \\
-\quad \text { No }\end{array}$ & $\begin{array}{l}72 \\
46\end{array}$ & $\begin{array}{l}61.0 \\
39.0\end{array}$ \\
\hline $\begin{aligned} & \text { Age of } \text { start attending: } \\
&- \text { <one year } \\
&- \text { 1<3years } \\
&- \text { 3<5years } \\
&- \text { 5to 6 years } \\
&\end{aligned}$ & $\begin{array}{c}9 \\
18 \\
32 \\
13\end{array}$ & $\begin{array}{c}7.6 \\
15.3 \\
27.1 \\
11.0\end{array}$ \\
\hline $\begin{array}{c}\text { Capacity of children / room: } \\
-\quad 40 \text { child } \\
-\quad 25 \text { child }\end{array}$ & $\begin{array}{l}44 \\
28\end{array}$ & $\begin{array}{l}61.1 \\
38.9\end{array}$ \\
\hline
\end{tabular}


Reda Mohamed Abd El-Gowad et. al.

Table (3): Frequency of the recurrent episodes of otitis media among the studied children' before and after implementation of the program in percentage distribution.

\begin{tabular}{|c|c|c|c|c|c|c|}
\hline \multirow{2}{*}{$\begin{array}{l}\text { The frequency of episodes } \\
\text { recurrent otitis media / year }\end{array}$} & \multicolumn{2}{|c|}{ Before } & \multicolumn{2}{|c|}{ Post 6 months } & \multirow[b]{2}{*}{$\chi^{2}$} & \multirow{2}{*}{$\mathbf{P}$} \\
\hline & $\mathbf{N}$ & $\%$ & $\mathbf{N}$ & $\%$ & & \\
\hline \multirow[t]{2}{*}{ Once - twice episode / year } & & & & & \multirow[t]{2}{*}{$\mathbf{r}$} & \multirow[t]{2}{*}{$\mathbf{r}$} \\
\hline & 33 & 28.0 & 109 & 92.4 & & \\
\hline \multirow[t]{2}{*}{3 - 4episodes / year } & & & & & 44.5 & $<0.001^{*}$ \\
\hline & 13 & 11.0 & 7 & 5.9 & & \\
\hline & & & & & \multirow{2}{*}{152.3} & \multirow{2}{*}{$<0.001 *$} \\
\hline$>4$ episodes / year & 72 & 61.0 & 2 & 1.7 & & \\
\hline Total & 118 & 100.0 & 118 & 100.0 & & \\
\hline & & & & & & \\
\hline
\end{tabular}

(*) Statistically significant at $\mathrm{P}>0.05$

Figure (1): Levels of mothers' reported practice, before, immediately after and post 6 months of the program implementation.

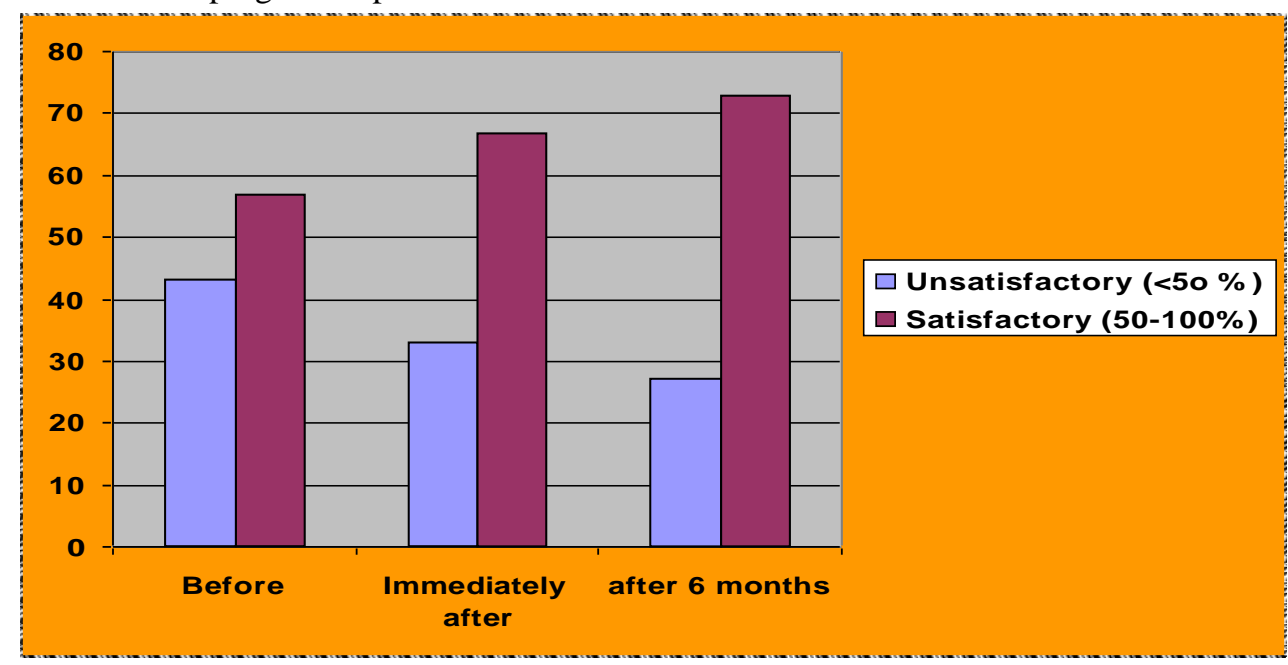

\section{Discussion}

As regards to the socio-demographic characteristics of the studied mothers the current study revealed that more than half of the studied mothers aged between $20<30$ years. This finding was in an accordance with Elsayed, (2016) who make a study titled as "Assessment of mother's knowledge and practices regarding care of their children with otitis media ", and stated that, there was the age of mothers was between $20<30$ years.

As observed from the present study, most of mothers were housewives, and a few of them were workes; it may be due to the fact that employed mothers had more time to gain information about the otitis media from multiple sources than unemployed ones. Kamuti, (2013) stated that usually employed mothers had good knowledge and more experience about their care and needs of their children.

In relation to the studied mothers' socioeconomic level, this study showed that, almost more than half of them are in low socioeconomic level. This comes in the same line with Adeyemo, (2012) in his study of "knowledge of caregivers on the risk factors of otitis media". In our opinion the recurrent otitis media 
THE IMPACT OF AN EDUCATIONAL PROGRAM FOR etc...

increased among the low socioeconomic families may be due to the low socioeconomic families have less finances and less resources to seek care for their sick children and to follow the medical and nursing instructions, this increase the risks of recurrent otitis media.

As regards to age of the studied children, the present study revealed that, more than two fifths of the studied children were in the age group from one year to less than 3 years of age This implies that younger children are more prone to otitis media than older infants. This finding is supported by Elsaied, (2014) about "Assessment of mother's knowledge and practices regarding care of their children with otitis media at Banha city", who observed that, the prevalence of the otitis media was found to be highest in the age group $1<4$ years. The susceptibility of young children may be explained by the lack of protective immunity and a shorter and less functional Eustachian tube.

According to the child's gender, the present study shows that more than half of the studied children were males . This finding was similar to results of study done by Tikaram et al., (2012) who found that, more than half of studied children were males. This comes in disagreement with Shaheen et al., (2012) who found that, girls are more affected than boys with otitis media, in their study entitled "prevalence and associated sociodemographic factors of chronic suppurative otitis media among rural primary school going children in Bangladesh".

Although breast feeding offers protection against many ear infections and the mothers' milk provides immune factors that help to protect the child from infections, but poor positioning during feeding could result in increased prevalence of recurrent otitis media among breast feeding children. About less than two thirds of the studied children were receiving breast feeding and more than half was in the supine position during feeding. This finding was supported by the results of the study entitled "feeding as a protective factor against otitis media in Thi-Qar" held by Neema et al., (2011) who stated that, there was an association between a reduction in number of otitis media episodes and breastfeeding because breastfeeding was viewed as a protective factor against upper respiratory tract infections.

Regarding to past medical history of studied children with otitis media and associated complication from recurrent otitis media, the finding of this study was illustrated that, one of the most common symptoms which represent, in more than half of studies children were ear pain

.This finding supported by Mali, (2012) in his study examining the "effectiveness of structured teaching program on knowledge of mothers of under five children on domiciliary management and prevention of upper respiratory tract infections", who found that, mothers were unable to identify the common signs \& symptoms of otitis media and most of them identified that ear pain and ear discharge are the most common signs \& symptoms of otitis media.

As regards the recurrent otitis media during winter season, the present study showed that, less than three quarter of the children suffered from recurrent otitis media during winter season. This finding is supported by Thabet, (2010) who found that more than two thirds of studied children had recurrent otitis media in winter season more than other seasons. In our opinion winter is at our doorstep and with it the incidence of viral respiratory tract infections and allergic conditions of the upper respiratory tract is on the rise. Both these conditions give rise to otitis media by blocking the Eustachian tube and impairing middle ear cavity drainage. This results in fluid accumulation which 
may become infected causing acute otitis media.

Concerning mothers' knowledge about otitis media, the finding of the present study revealed that, a few of them answered correctly before the program while this percentage improved to majority of them immediately after and post 6 months of the program implementation . This finding in agreement with Tikaram et al., (2012) who cited that otitis media is a broad term that includes; acute otitis media, chronic otitis media and otitis media with effusion and reported that acute otitis media as an infection of the middle ear with acute onset, presence of middle ear effusion and signs of middle ear inflammation and commonly occurs in children and it is the most frequent specific diagnosis in children who are febrile. Also this finding in agreement with Lieberthal et al., (2013) who cited that chronic otitis media means a recurrent or persistent inflammation of the middle ear. It is usually associated with upper respiratory infection, a cough or runny and stuffy nose. It is the most commonly caused by trapped moisture in the ear and by minor injury to the ear canal.

Regarding the reasons of occurrence of otitis media in children more than adults the result of the current study found that the minority of studied mothers mentioned all reasons occurrence of otitis media in children more than adults before the implementation of the program and this improved to majority of them immediately after the implementation of the program and more than three quarter of them months later . This finding was similar to the view of Ilechukwu et al., (2014) who reported that the Eustachian tube is shorter and more horizontal and straighter angle than in adult ear so, children are liable to otitis media due to increased pollution, where children are exposed to many respiratory infections.

In relation to the studied mothers' knowledge about causes and predisposing factors for recurrence of otitis media in children, the study findings revealed that low percent of them know about them before implementation of the educational program, while after the program implementation this finding improved. This result can be explained by previous experience with the infants or their siblings or by being up-to-date with new information about otitis media. Pacifier usage was viewed to have a strong association with the occurrence of otitis media in infants in a study entitled "a comprehensive review of evidence and current recommendations related to pacifier usage" by Antonia and Nelson, (2012) who were reported that, the pacifier usage negatively impacts the function of the Eustachian tube.

Regarding the studied mothers' knowledge about the signs and symptoms of acute otitis media in children, it was cleared that, less than half of the studied mothers mentioned all the signs and symptoms of acute otitis media in children before the implementation of the program and this percentage improved to majority of them immediately after the implementation of the program and 6 months later. This implies that the studied mothers had a fair concept about signs \& symptoms of otitis media. This finding was contrasted by Mali, (2012) in his study examining the "effectiveness of structured teaching program on knowledge of mothers of under five children on domiciliary management and prevention of upper respiratory tract infections", who found that, mothers were unable to identify the common signs \& symptoms of otitis media and most of them identified that otalgia and otorrhea are the most common signs \& symptoms of otitismedia. 
In relation to the studied mothers knowledge about complications and the preventive measures for recurrence of otitis media in children, the study findings revealed that low percent of them know about them before implementation of the educational program, while after the program implementation this finding improved . This finding was supported by Kamuti, (2013) in his study describing "perception and health care seeking practices of guardians of young children towards chronic suppurative otitis media in Machakos City, Kenya", who found that, the majority of the studied mothers had the perception that untreated otitis media can lead to deafness and disturbed behavior. Also this finding was supported by Yousef et al., (2015) in their study of the "impact of educational program on the management of chronic suppurative otitis media among children" where they found that, the mothers had the right concept about prevention of otitis media, which is achieved by avoiding the etiological factors of otitis media. This flags that mothers have sufficient knowledge about preventive measures of otitis media.

The findings of the present study have demonstrated statistically significant differences between before and post 6 months of the program implementation in mothers' knowledge. This was documented by the increase in the percentages of mothers who have "good" knowledge scores. This improvement could be explained by the positive impact of the educational program on the mothers' knowledge. Also, it could be explained by the interest of the mothers with the teaching methods and the audiovisual materials used in the educational program.

Regarding the reported practice to dealing of the mothers at the onset of signs of ear infection the present study found that, less than one quarter of the studied mothers goes to the doctor immediately before the implementation of the program and this percentage improved to more than three quarter of them immediately after the implementation of the program and less than three quarter 6 months later. This finding supported by Rouusounides et al., (2011) who found that, the main symptoms considered important and would drive parents to the doctor's office included earache and fever. Regarding the reported practice of the mother for reliving the ear pain the present study showed that, about of one quarter of the studied mothers apply warm compress on the child's ear before the implementation of the program and this percentage improved to majority of them immediately after the implementation of the program and 6 months later. This finding was agreed with the findings of the study of Rosenfeld et al., (2013) who found that, treatment practices in the community were more or less uniform in by most caregivers, while a doctor's opinion was often sought for ear discharge by half of caregivers. Parents of higher socioeconomic status were more likely to use home remedies than those of lower socioeconomic status. This may be due to the interventions for relieving pain may be differ according to many factors such as mothers believes about pain, knowledge of mothers, education of mothers, social level and economic status. This finding supported by Price \& Gwin, (2012) who found that alleviating the pain associated with otitis media is a primary concern for caregivers. Warm compress may be applied to the ear. The child can be placed on the affected side with the ear on the top of a hot water bottle (temperature of water $115^{\circ} \mathrm{F}$ or $46^{\circ} \mathrm{C}$ ) or in heating pad.

Regarding the reported practice of the mother regarding dealing with wax in the ear the present study showed that, the majority of studied mothers were removed the waxy material from the child ear by 
using usual a plunger before the implementation of the program and this percentage decreased immediately after the implementation of the program and 6 months later. This finding was supported by Taylor et al., (2012) who stated that, ear picks are a commonly used item and preferred for ear wax removal. The cleaning of ears is often performed by a parent on a child.

Regarding the reported practice of the mother regarding ear care during inflammation the present study showed that, less than one quarter of the studied mothers using special tools for the child before the implementation of the program and this percentage improved to majority of them immediately after the implementation of the program and more than three quarter 6 months later. This finding was supported by Elsayed, (2016) who found that, almost less than half of the studied mothers reported that they perform ear care using tap water only. This finding was in contrast with Elsaied, (2014) who reported that, the majority of the studied mothers didn't think that it was crucial to clean the inner part of the infant's ear before ear drop administration. Meanwhile, in another study entitled "knowledge and beliefs about ear and hearing health among mothers of young children in a rural community in South India".

Regarding total mothers reported practices the present study found that, more than two fifths of the studied mothers had "unsatisfactory" reported practice before the program while immediately after the program implementation and 6 months later, this percent decreased to approximately one third and more than one quarter respectively. From the view of point of the researcher it may be due to deficit of knowledge regarding care of their children with otitis media. This finding was asserted during researcher interviews with mothers as mother who hadn't knowledge; she had poor practices for care of the child. This result was supported by Elsaied, (2014) who found that, almost less than three quarters of the studied mothers had unsatisfactory practices regarding care of their infants suffering from otitis media before intervention.

Regarding the frequency of episodes recurrent otitis media among the studied children the current study found that, more than two thirds of them their recurrence were 4episodes or more per year before program. After implementation of the educational program the children improved as majority of children had recurrent otitis media once or twice episode per year. Highly statistical significant differences were found between before\& post 6 months of the program implementation regarding to the frequency of recurrent otitis media. This finding was supported by the finding of study done by Thabet (2010) who found that about two thirds of them have four episodes or more per year before program. After implementation of the educational program the children were improved as majority of children had recurrent otitis media once or twice episode per year there was highly statistical significant differences between before\& post 6 months of the program implementation regarding to the frequency of recurrent otitis media.

The present study found that, there were no statistically significant relations between the studied mothers' knowledge and their reported practice before, immediately after as well as post 6 months of the program implementation . The result of this study was inconsistent with Elsaied, (2014) who found that, there was statistical significant correlation ( $\mathrm{r}$ $=.268, \mathrm{P}<0.05$ ) between mothers' total knowledge regarding otitis media in children and their total practices before intervention. 
THE IMPACT OF AN EDUCATIONAL PROGRAM FOR etc...

.Conclusion
There was a positive impact of the
educational program in improving
mothers' knowledge as well as their
reported practices about otitis medias well
as prevent recurrent of otitis media.

\section{Recommendations}

The following recommendations are to be considered:

- Regular and continuous health educational programs are essential for families about otitis media.

- Mass media should have a role in educating families with emphasize on the physical, psychological, social and financial needs of children with otitis media and their families.

- Health education programs should be directed to mothers to encourage breastfeeding.

\section{References}

1. Adeyemo, A.A. (2012): Knowledge of Caregivers on the Risk Factors of Otitis Media. Indian Journal of Otology, 18(4): 184-188.

2. Antonia, M. and Nelson, R.N.C. (2012): A Comprehensive Review of Evidence and Current Recommendations Related to Pacifier Usage. Journal of Pediatric Nursing, 27: 690-699

3. Barenkamp, S. J. (2015): Editorial Commentary: Respiratory Viruses and Otitis Media in Young Children. Clinical infectious disease, 60(1): 1011.

4. Djalilian, H.R. (2015): Symptom: Recurrent Otitis Media. Hearing Journal, 68(2): 19-24.

5. Djurhuus, B.D., Christensen, K., Skytthe, A. and Faber, C.E. (2015): The impact of Ventilation Tubes in Otitis Media on the Risk of Cholesteatoma on A National Level. International ournal of pediatric Otorhinolaryngology, 79(4):605-9.

6. Elsaied, R.R. (2014): Assessment of Mother's Knowledge and Practices
Regarding Care of their Children with Otitis Media at Banha City. Tanta Scientific Nursing Journal, 7: 64-81.

7. Elsayed, (2016): Assessment of mother's knowledge and practices regarding care of their children with otitis media

8. Hansen, M.P., Hewlett, J., Del-Mar, C. and Hoffmann, T.C. (2015): Parents' Beliefs and Knowledge about the Management of Acute Otitis Media: A Qualitative Study. BMC Family Practice, 16:82.

9. Humaid, A.H., Ashraf, A.H., Masood, K.A., Nuha, A.H., Saleh, A.D. and Awadh A.M. (2014): Prevalence and Risk Factors ofOtitis Media with Effusion in School Children in Qassim Region of Saudi Arabia. International Journal of Health Sciences, 8(4):325-334.

10. Ilechukwu, G.C., Ilechukwu, C.G.A., Ubesie, A.C., Ojinnaka, C.N., Emechebe, G.O. and Iloh, K.K. (2014): Otitis Media in Children: Review Article. Open Journal of Pediatrics, 4:47-53.

11. Kamuti, B.W. (2013): Perception and Health Care Seeking Practices of Guardians of Young Children towards Chronic Suppurative Otitis Media in Machakos City, Kenya, Master Thesis, Public Health and Epidemiology, The School of Pure and Applied Sciences, Kenyatta University, PP.68-76.

12. Lieberthal AS, Carroll AE, \& Chonmaitree T, (2013): The diagnosis and management of acute otitis media. Pediatrics; 131:e964. Available at:https://www2.luriechildrens.org/ce /online/article.

13. Mali, M.S. (2012): Effectiveness of Structured Teaching Program on Knowledge of Mothers of Under Five Children on Domiciliary Management and Prevention of Upper Respiratory 
Tract Infections. Sinhgabad e Journal of Nursing, 2(2): 44-46.

14. Naguib, M.A., El-Hennawi, D., Hessam, W.F., El-Tabbakh, M.T., Gamal, A. (2013): Acute Otitis Media in Children of Ismailia city: A Bacteriological Study. Egyptian Journal of Otolaryngology, 29(1):229-230.

15. Neema, M., Majeed, M.N. and AlGuzi, A.A.S. (2011): Breast Feeding As A Protective Factor Against Otitis Media in Thi-Qar. Kufa Medical Journal, 14(1): 309-317.

16. Padmaja A., (2015): Child Health Nursing: Nursing Process Approach, $1^{\text {st }}$ ed, chapter 19 , Eye, Ear, and Throat function, Pearson education, New Jersey.p279.

17. Price, D.L. and Gwin, J.F. (2012): Pediatric Nursing. An Introductory Textbook. $\quad 10^{\text {th }} \quad$ ed., China: Saunders/Elsavier, PP.141-144.

18. Rosenfeld, R. M., Schwartz, S. R., Pynnonen, M. A., Tunkel, D. E., Hussey, H. M., Fichera, J. S., ... \& Haynes, D. S. (2013). Clinical practice guideline: tympanostomy tubes in children-executive

summary. Otolaryngology--Head and Neck Surgery,149 (1), 8-16. available at, https://medlineplus.gov/ency/article.

19. Scott, W. and Hunt, A. (2011): The Important Role of Fathers in the Lives of Young Children. Journal of Family Issues, 29(9): 1211-1244.
20. Shaheen, M.M., Raquib, A. and Ahmad, S.M. (2012): Prevalence and Associated Socio-demographic Factors of Chronic Suppurative Otitis Media among Rural Primary School Going Children in Bangladesh. International Journal of Pediatric Otorhinolaringology, 76(48): 12011204.

21. Taylor, S., Marchisio, P., Vergison, A., Harriague, J., Hausdorff, W. P., \& Haggard, M. (2012). Impact of pneumococcal conjugate vaccination on otitis media: a systematic review. Clinical Infectious Diseases, 54(12), 1765-1773.

22. Thabet, A.M., (2016): effect of an educational program for parents of children with recurrent otitis media during early childhood on prevention of the recurrence of otitis media at Assiut university hospital.

23. Tikaram, A., Chew, Y.K., Zulkiflee, A.B., Chong, A.W. and Prepageran, N. (2012): Prevalence and Risk Factors Associated with Otitis Media with Effusion in Children Visiting Tertiary Care Center in Malaysia. The International Medical Journal of Malaysia, 11(1): 37-40.

24. Yousef, Y.E., Abo EI-Magd, E.A., El-Asheer, O.M. and Kotb, S.(2015): Impact of Educational Program on the Management of Chronic Suppurative Otitis Media among Children. International Journal of Otolaryngology, 624317. 